\title{
The Hammett correlation between distyrylbenzene substituents and chemiluminescence efficiency providing various $\rho$-values for peroxyoxalate chemiluminescence of several oxalates
}

Takayuki Maruyama, Susumu Narita, and Jiro Motoyoshiya*

Applied Chemistry Course, Division of Chemistry and Materials, Faculty of Textile Science and Technology, Shinshu University, Ueda, Nagano 386-8567, Japan

* Corresponding author: Tel.: +81-268-21-5402; fax: +81-268-21-5391.

E-mail address: jmotoyo@shinshu-u.ac.jp (J. Motoyoshiya)

Key Words:

Peroxyoxalate chemiluminescence

Hammett correlation

High-energy intermediate

Frontier molecular orbital theory

\begin{abstract}
Peroxyoxalate chemiluminescence (PO-CL) was investigated using eight oxalates with various phenol moieties and the distyrylbenzene (DSB) fluorophores with various substituents. The $\rho$-values in the Hammett correlation between the substituent constants $\left(\sigma_{p}{ }^{+}\right)$of the DSBs and the singlet chemiexcitation yields $\left(\Phi_{\mathrm{S}}\right)$ for the PO-CL reactions varied from -0.50 to -1.01 depending on the oxalate structure, and the reactive oxalates tended to afford the higher absolute $\rho$-values but with a few exceptions. Based on the CIEEL mechanism, these experimental observations suggest that the aryloxy groups still remain in the 1,2-dioxetanones (DOTs), which are the postulated high-energy intermediates, and control the electronic properties of DOTs as electron-acceptors. The LUMO energies of the DOTs calculated by the ab initio method with a B3LYP/6-31g(d) basis set reveal that the lower the DOT-LUMO energies, the higher the absolute $\rho$-values were provided for the corresponding oxalates, as predicted by the frontier molecular orbital (FMO) theory. Thus, the chemical species interacting with the DSBs would be not unitary and will be DOTs.
\end{abstract}




\section{Introduction}

Since Chandross first discovered the peroxyoxalate chemiluminescence (PO-CL) reaction [1], much attention has been paid to this CL and chemists have tried to elucidate its mechanism for a long time [2-25] because of high efficiency [23] and usefulness in analytical chemistry [26,27]. Among the several peroxides proposed so far as the high-energy intermediates (HEIs) capable of generating the excited fluorophores during their decomposition, the four-membered cyclic peroxides, such as 4-aryloxy-4-hydroxy-1,2-dioxetane-3-one (DOT) and 1,2-dioxetne-3,4-dione (DOD), have been the most frequently proposed $[3,4,6,7,9,10,14,19,21,22]$. However, these intermediates have never been captured nor isolated. There have been studies observing labile intermediates by NMR using the highly reactive oxalates [28,29]. In addition, the EPR detection of a biradical as a trace of the formed DOD during the reaction of the oxalyl chloride and hydrogen peroxide spectra was very recently reported [30]. CIEEL (chemically initiated electron exchange luminescence) mechanism [31,32] was applied to the PO-CL $[33,34]$, and explained experimental evidences [35-40]. According to this mechanism, an electron transfer from the fluorophores to the HEI, such as the DOTs or DOD, takes place to form a pair consisting of the carbon dioxide radical anion and the fluorophore radical cation during the decomposition of the HEI, which is followed by a back electron transfer to produce the excited fluorophores (Scheme 1). In spite of a steady accumulation of knowledge and many recent efforts made by a number of chemists, identification of the HEIs interacting with fluorophores still remains unclear.

It is important to examine the effect of the oxalate structures on the CL behavior [22], because there have been only a few reports in which a number of oxalates were employed, and new aspects can be obtained by comparing the CL behavior of the different oxalates, if the structure of the HEI as the electron-acceptors is not unitary and might depend on the oxalate structures. On the other hand, the 1,4-distyrylbenzene (DSB) derivatives are strongly fluorescent $[41,42]$ and good emitters among the numerous fluorophores so far used for the PO-CL reactions $[38,39]$ due to availability by the simple synthetic method and capability of modulating their electronic properties by the substituents. During our continuous studies of the DSB enhanced PO-CL, some remarkable electronic effects on the CL efficiency have been observed. Therefore, it is expected that there is a possibility of identification of the HEIs when the CL behavior using various DSBs and oxalates is investigated in detail. In this paper, we report the Hammett correlation between the DSB substituents and the behavior of the DSB enhanced PO-CL reactions employing the eight aryl oxalates and give consideration to the HEIs in connection with the interpretation of the observed CL behavior using the frontier molecular orbital (FMO) theory. 


\section{Experimental details}

\subsection{Materials}

Melting points were determined using a hot stage microscope apparatus and were uncorrected. Proton nuclear magnetic resonance ${ }^{1} \mathrm{H}$ - and ${ }^{13} \mathrm{C}-\mathrm{NMR}$ spectra were measured on a Bruker AVANCE-400 at $400 \mathrm{MHz}$ for ${ }^{1} \mathrm{H}-\mathrm{NMR}, 100 \mathrm{MHz}$ for ${ }^{13} \mathrm{C}-\mathrm{NMR}$, respectively, in $\mathrm{CDCl}_{3}$. The chemical shifts $(\delta)$ are reported in ppm downfield from TMS as internal standard or from the residual solvent peak for ${ }^{1} \mathrm{H}$ - and ${ }^{13} \mathrm{C}$-NMR. Coupling constants $(J)$ are reported in Hz. Low and high resolution mass spectra (MS) were recorded by the JEOL JMS-K9 spectrometers. Elemental analysis was recorded on a Perkin-Elmer 2400CHN elemental analyzer. Analytical TLC was carried out on precoated silica gel 60F-254 plates (E. Merck). Column chromatography was performed on silica gel (E. Merck). Absorption and fluorescence spectra were recorded on a U-3310 spectrometer (Hitachi) and on a RF-5000 spectrometer (Shimadzu), respectively. The measurements of the total CL quantum yield $\left(\Phi_{\mathrm{CL}}\right)$ were carried out by a photon-counting method using a Hamamatsu Photonics R464 photomultiplier connected to a photon-counting unit (C3866) and a photon-counting board M8784, and the luminol CL $\left[\Phi_{\mathrm{CL}}=0.09\right.$ in dimethyl sulfoxide, Lit. J. Lee, H. H. Seliger, Photochem. Photobiol. 15 (1972) 227-237] was used as the standard in DMSO for calibration of the photomultiplier tube.

All commercially available chemicals and solvents were of the highest purity or purified by the standard method. A series of the oxalates employed in the present study, all of which are known compounds, are listed in Table 1. They were prepared from the reaction of oxalyl chloride and two equivalents of the corresponding phenols in the presence of triethylamine in benzene, while the unsymmetrical oxalate 4-CPPO was prepared from the reaction of oxaly chloride and one equivalent phenol in the presence of triethylamine followed by the addition of another p-chlorophenol. DNPO [bis(2,4-dinitrophenyl) oxalate] was supplied by Tokyo Chemical Industries (TCI).

\subsubsection{1,4-Bis(2-ethylhexyloxy)-2,5-bis(diethylphosphonomethyl)benzene}

2-Ethylhexyl bromide (35 g, $180 \mathrm{mmol})$ was added dropwise to a solution of hydroquinone $(10 \mathrm{~g}$, $91 \mathrm{mmol})$ and potassium hydroxide $(13 \mathrm{~g}, 230 \mathrm{mmol})$ in ethanol $(80 \mathrm{~mL})$ and stirred for $2 \mathrm{~h}$ at $80^{\circ} \mathrm{C}$. After removal of the solvent and the addition of ether, the inorganic by-products were removed by washing with saturated $\mathrm{NaHCO}_{3}$ aqueous solution and brine. The organic phase was dried over anhydrous $\mathrm{Na}_{2} \mathrm{SO}_{4}$. After the $\mathrm{Na}_{2} \mathrm{SO}_{4}$ was filtered out and the solvent was distilled away, the crude product was purified by column chromatography on silica gel (eluant: $n$-hexane) to afford 
1,4-bis(2-ethylhexyloxy)benzene as a colorless liquid. Yield: 50\% (15 g); ${ }^{1} \mathrm{H}$ NMR (400 MHz,

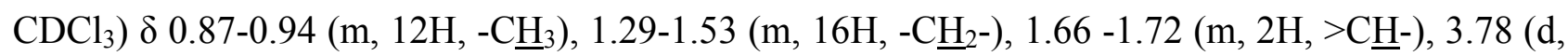
$\left.4 \mathrm{H},-\underline{\mathrm{C}}_{2} \mathrm{O}-, J=5.8 \mathrm{~Hz}\right), 6.82(\mathrm{~s}, 4 \mathrm{H}, \mathrm{Ar}-\underline{\mathrm{H}})$. After a solution of 1,4-bis(2-ethylhexyloxy)benzene $(9.5 \mathrm{~g}, 28 \mathrm{mmol})$ and paraformaldehyde $(1.9 \mathrm{~g})$ in hydrobromic acid $(48 \%, 60 \mathrm{~mL})$ and acetic acid $(90 \mathrm{ml})$ was stirred for $17 \mathrm{~h}$ at $70^{\circ} \mathrm{C}$, the solution was cooled to room temperature for $2 \mathrm{~h}$. The deposited crystals were filtered and washed by water and $n$-hexane to afford 1,4-bis(2-ethylhexyloxy)-2,5-bis(bromomethyl)benzene as colorless crystals. Yield: 82\% (12 g); ${ }^{1} \mathrm{H}$ NMR $\left(400 \mathrm{MHz}, \mathrm{CDCl}_{3}\right) \delta 0.89-0.97\left(\mathrm{~m}, 12 \mathrm{H},-\underline{\mathrm{CH}}_{3}\right), 1.32-1.61\left(\mathrm{~m}, 16 \mathrm{H},-\underline{\mathrm{C}}_{2}-\right)$, 1.72-1.78 (m, $2 \mathrm{H},>\mathrm{CH}-), 3.87$ (d, 4H, $\left.-\underline{\mathrm{H}}_{2} \mathrm{O}, J=5.6 \mathrm{~Hz}\right), 4.52\left(\mathrm{~s}, 4 \mathrm{H},-\mathrm{C}_{2} \mathrm{Br}\right), 6.85$ (s, 2H, Ar- $\left.\underline{\mathrm{H}}\right)$. A mixture of 1,4-bis(2-ethylhexyloxy)-2,5-bis(bromomethyl)benzene (11 g, $21 \mathrm{mmol}$ ) and triethyl phosphite (8.8 $\mathrm{g}, 53 \mathrm{mmol}$ ) was stirred for $1.5 \mathrm{~h}$ at $130^{\circ} \mathrm{C}$ with removing by-product (bromoethane) using distilling receiver. The crude product was purified by column chromatography on silica gel (eluant: hexane/ethyl acetate $=5 / 1$ ) to afford 1,4-Bis(2-ethylhexyloxy)-2,5-bis(diethylphosphonomethyl)benzene as a colorless liquid. Yield: 96\% (13 g); ${ }^{1} \mathrm{H}$ NMR $\left(400 \mathrm{MHz}, \mathrm{CDCl}_{3}\right) \delta$ 0.88-0.94 (m, 12H, - $\left.\underline{\mathrm{H}}_{3}\right), 1.23\left(\mathrm{t}, 12 \mathrm{H},-\mathrm{OCH}_{2} \underline{\mathrm{C}}_{3}, J=7.1 \mathrm{~Hz}\right), 1.29-1.56\left(\mathrm{~m}, 16 \mathrm{H},-\underline{\mathrm{C}}_{2}-\right)$,

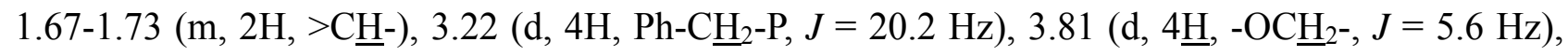
3.96-4.06 (m, 8H, $\left.-\mathrm{OCH}_{2} \mathrm{CH}_{3}\right), 6.94(\mathrm{~s}, 2 \mathrm{H}, \mathrm{Ph}-\underline{\mathrm{H}})$. This compound was used for the preparation of the following distyrylbenzenes (1a-g) without further purification.

\subsubsection{1,4-Bis(2-ethylhexyloxy)-2,5-bis(p-dimethylaminostyryl)benzene (1a)}

A solution of 1,4-bis(2-ethylhexyloxy)-2,5-bis(diethylphosphonomethyl)benzene (0.50 g, 0.79 $\mathrm{mmol})$ and $p$-dimethylaminobenzaldehyde $(2.5 \mathrm{~g}, 1.7 \mathrm{mmol})$ in tetrahydrofuran (THF) (5 $\mathrm{mL})$ was added dropwise to a solution of ${ }^{t} \mathrm{BuOK}(0.31 \mathrm{~g}, 2.8 \mathrm{mmol})$ in THF $(10 \mathrm{~mL})$ and stirred for $2 \mathrm{~h}$ at room temperature. After removal of the solvent and the addition of $1 \mathrm{M}$ hydrochloric acid for neutralization, the deposited crystal was filtered and washed by cooled hexane to afford yellow crystals. Yield: $54 \%(0.26 \mathrm{~g})$; mp 159-160 C; $1 \mathrm{H}$ NMR $\left(400 \mathrm{MHz}, \mathrm{CDCl}_{3}\right) \delta 0.92(\mathrm{t}, 6 \mathrm{H},-\mathrm{CH} 3, J=$ $7.0 \mathrm{~Hz}), 0.99$ (t, 6H, - $\left.\underline{\mathrm{H}}_{3}, J=7.5 \mathrm{~Hz}\right), 1.28-1.67$ (m, 16H, - $\left.\underline{\mathrm{H}}_{2}-\right)$, 1.74-1.88 (m, 2H, >C프-), 2.98

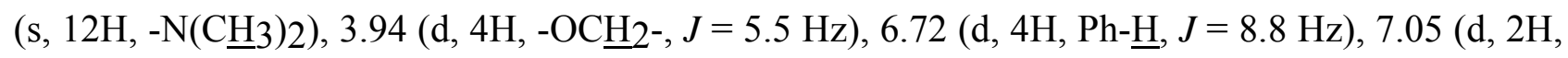

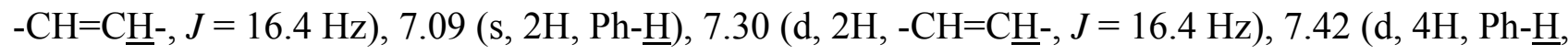
$J=8.8 \mathrm{~Hz})$; 13C NMR (100 MHz, $\left.\mathrm{CDCl}_{3}\right) \delta$ 11.77, 14.56, 23.55, 24.68, 29.71, 31.36, 40.26, 40.93, $72.21,110.29,112.95,119.79,127.17,127.21,127.89,128.67,150.34,151.33 ; \mathrm{MS}(\mathrm{m} / \mathrm{z}) 624\left(\mathrm{M}^{+}\right)$; Anal. Calcd for $\mathrm{C}_{42} \mathrm{H}_{60} \mathrm{~N}_{2} \mathrm{O}_{2}$ : C, 80.72; H, 9.68; N, 4.48. Found: C, 80.45; H, 9.87; N, 4.34.

\subsubsection{1,4-Bis(2-ethylhexyloxy)-2,5-bis(p-methoxystyryl)benzene (1b)}


This compound was prepared in a manner similar to the procedure described above using 1,4-bis(2-ethylhexyloxy)-2,5-bis(diethylphosphonomethyl)benzene $\left(\begin{array}{llll}0.50 & \mathrm{~g}, & 0.79 \mathrm{mmol}) & \text { and }\end{array}\right.$ p-anisaldehyde $(2.3 \mathrm{~g}, 1.7 \mathrm{mmol})$ and ${ }^{t} \mathrm{BuOK}(0.31 \mathrm{~g}, 2.8 \mathrm{mmol})$. Yield: 39\% (0.19 g) as light yellow crystals; mp 86-87 $\mathrm{C} ;{ }^{1} \mathrm{H}$ NMR $\left(400 \mathrm{MHz}, \mathrm{CDCl}_{3}\right) \delta 0.92$ (t, $\left.6 \mathrm{H},-\mathrm{C}_{3}, J=7.1 \mathrm{~Hz}\right), 0.99$ (t,

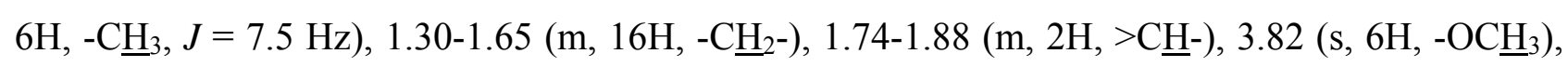
$3.94\left(\mathrm{~d}, 4 \mathrm{H},-\mathrm{OC}_{2_{2}}-, J=5.5 \mathrm{~Hz}\right), 6.90(\mathrm{~d}, 4 \mathrm{H}, \mathrm{Ar}-\underline{\mathrm{H}}, J=8.8 \mathrm{~Hz}), 7.05-7.13(\mathrm{~m}, 4 \mathrm{H},-\mathrm{CH}=\mathrm{C} \underline{\mathrm{H}}-$, $\operatorname{Ar}-\underline{H}), 7.36(\mathrm{~d}, 2 \mathrm{H},-\mathrm{CH}=\mathrm{C} \underline{\mathrm{H}}-, \quad J=16.5 \mathrm{~Hz}), 7.46(\mathrm{~d}, 4 \mathrm{H}, \mathrm{Ar}-\underline{\mathrm{H}}, J=8.7 \mathrm{~Hz}) ;{ }^{13} \mathrm{C} \mathrm{NMR}(100 \mathrm{MHz}$, $\left.\mathrm{CDCl}_{3}\right) \delta 11.76,14.54,23.54,24.68,29.70,31.38,40.23,55.73,72.22,110.54,114.55,121.91$, 127.17, 128.04, 128.43, 131.36, 151.47, 159.55; MS (m/z) $598\left(\mathrm{M}^{+}\right)$; Anal. Calcd for $\mathrm{C}_{40} \mathrm{H}_{54} \mathrm{O}_{4}: \mathrm{C}$, 80.22; H, 9.09. Found: C, 80.18; H, 9.28.

\subsubsection{1,4-Bis(2-ethylhexyloxy)-2,5-bis(p-methylstyryl)benzene (1c)}

This compound was prepared in a manner similar to the procedure described above using 1,4-bis(2-ethylhexyloxy)-2,5-bis(diethylphosphonomethyl)benzene $\left(\begin{array}{llll}1.0 & \mathrm{~g}, & 1.6 \mathrm{mmol}) & \text { and }\end{array}\right.$ p-tolualdehyde $(0.40 \mathrm{~g} 3.3 \mathrm{mmol})$ and ${ }^{t} \mathrm{BuOK}(0.61 \mathrm{~g}, 5.5 \mathrm{mmol})$. Yield: $35 \%(0.31 \mathrm{~g})$ as light yellow crystals; mp $113-114^{\circ} \mathrm{C} ;{ }^{1} \mathrm{H} \mathrm{NMR}\left(400 \mathrm{MHz}, \mathrm{CDCl}_{3}\right) \delta 0.92\left(\mathrm{t}, 6 \mathrm{H},-\underline{\mathrm{C}}_{3}, J=7.0 \mathrm{~Hz}\right), 0.99(\mathrm{t}$, $\left.6 \mathrm{H},-\underline{\mathrm{CH}}_{3}, J=7.5 \mathrm{~Hz}\right), 1.29-1.66\left(\mathrm{~m}, 16 \mathrm{H},-\underline{\mathrm{C}}_{2}-\right), 1.75-1.87(\mathrm{~m}, 2 \mathrm{H},>\mathrm{C} \underline{\mathrm{H}}-), 2.35\left(\mathrm{~s}, 6 \mathrm{H},-\underline{\mathrm{C}}_{3}\right)$, $3.94\left(\mathrm{~d}, 4 \mathrm{H},-\mathrm{OC}_{2}-, J=5.5 \mathrm{~Hz}\right), 7.07-7.14(\mathrm{~m}, 6 \mathrm{H},-\mathrm{CH}=\mathrm{C} \underline{\mathrm{H}}-, \mathrm{Ph}-\underline{\mathrm{H}}), 7.16$ (d, 4H, Ph- $\underline{\mathrm{H}}, J=8.1$ $\mathrm{Hz}), 7.42$ (d, 2H, Ph- $\underline{\mathrm{H}}, J=8.0 \mathrm{~Hz}), 7.45$ (d, 2H, $-\mathrm{CH}=\mathrm{C} \underline{\mathrm{H}}-, J=16.4 \mathrm{~Hz}) ;{ }^{13} \mathrm{C}$ NMR $(100 \mathrm{MHz}$, $\left.\mathrm{CDCl}_{3}\right) \delta 11.78,14.56,21.69,23.56,24.70,29.73,31.40,40.25,72.24,110.69,123.01$, 126.81127.25, 128.94, 129.81, 135.73, 137.63, 151.58; MS (m/z) $566\left(\mathrm{M}^{+}\right)$; Anal. Calcd for $\mathrm{C}_{40} \mathrm{H}_{54} \mathrm{O}_{2}$ : C, 84.75; H, 9.60. Found: C, 84.59; H, 9.83.

\subsubsection{1,4-Bis(2-ethylhexyloxy)-2,5-distylylbenzene (1d)}

This compound was prepared in a manner similar to the procedure described above using 1,4-bis(2-ethylhexyloxy)-2,5-bis(diethylphosphonomethyl)benzene $\left(\begin{array}{llll}0.50 & \mathrm{~g}, & 0.79 \mathrm{mmol}) & \text { and }\end{array}\right.$ benzaldehyde $(0.18 \mathrm{~g} 1.7 \mathrm{mmol})$ and ${ }^{t} \mathrm{BuOK}(0.31 \mathrm{~g}, 2.8 \mathrm{mmol})$. Yield: 50\% (0.21 g) as yellow green crystals; mp 86-87 ${ }^{\circ}$; ${ }^{1} \mathrm{H}$ NMR $\left(400 \mathrm{MHz}, \mathrm{CDCl}_{3}\right) \delta 0.92\left(\mathrm{t}, 6 \mathrm{H},-\mathrm{C}_{3}, J=7.0 \mathrm{~Hz}\right), 0.99$ (t,

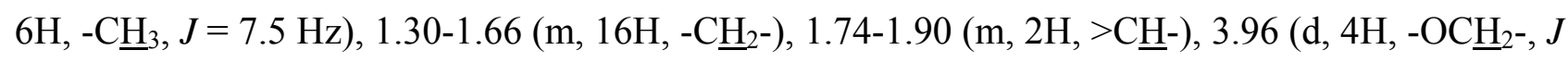
$=5.5 \mathrm{~Hz}), 7.10-7.19$ (m, 4H, $-\mathrm{CH}=\mathrm{C} \underline{\mathrm{H}}-, \mathrm{Ph}-\underline{\mathrm{H}}), 7.24$ (t, 2H, Ph- $\underline{\mathrm{H}}, J=7.4 \mathrm{~Hz}), 7.35$ (t, 4H, Ph- $\underline{\mathrm{H}}, J$

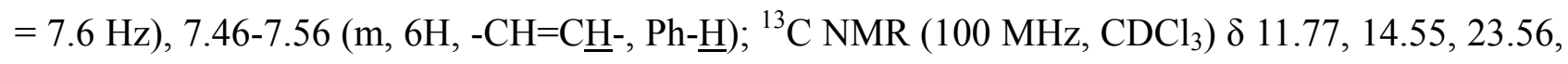
24.70, 29.73, 31.40, 40.24, 72.24, 110.79, 123.98, 126.90, 127.27, 127.80, 129.09, 138.47, 151.66; MS (m/z): $538\left(\mathrm{M}^{+}\right)$; Anal. Calcd for $\mathrm{C}_{38} \mathrm{H}_{50} \mathrm{O}_{2}:$ C, 84.71; H, 9.35. Found: C, 84.56; H, 9.60. 


\subsubsection{1,4-Bis(2-ethylhexyloxy)-2,5-bis(p-chlorostyryl)benzene (1e)}

This compound was prepared in a manner similar to the procedure described above using 1,4-bis(2-ethylhexyloxy)-2,5-bis(diethylphosphonomethyl)benzene $\left(\begin{array}{llll}0.50 & \mathrm{~g}, & 0.79 \mathrm{mmol}) & \text { and }\end{array}\right.$ p-chlorobenzaldehyde $(0.23 \mathrm{~g} 1.7 \mathrm{mmol})$ and ${ }^{t} \mathrm{BuOK}(0.31 \mathrm{~g}, 2.8 \mathrm{mmol})$. Yield: 43\% (0.20 g) as yellow green crystals; mp $104-106{ }^{\circ} \mathrm{C} ;{ }^{1} \mathrm{H} \mathrm{NMR}\left(400 \mathrm{MHz}, \mathrm{CDCl}_{3}\right) \delta 0.91\left(\mathrm{t}, 6 \mathrm{H},-\underline{\mathrm{H}}_{3}, J=7.0 \mathrm{~Hz}\right)$, $0.99\left(\mathrm{t}, 6 \mathrm{H},-\underline{\mathrm{C}}_{3}, J=7.5 \mathrm{~Hz}\right), 1.28-1.65\left(\mathrm{~m}, 16 \mathrm{H},-\mathrm{C}_{2}{ }^{-}\right), 1.75-1.85(\mathrm{~m}, 2 \mathrm{H},>\mathrm{C} \underline{\mathrm{H}}-), 3.94(\mathrm{~d}, 4 \mathrm{H}$,

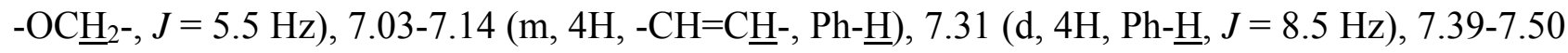
$(\mathrm{m}, 6 \mathrm{H},-\mathrm{CH}=\mathrm{CH}-, \mathrm{Ph}-\underline{\mathrm{H}}) ;{ }^{13} \mathrm{C} \mathrm{NMR}\left(100 \mathrm{MHz}, \mathrm{CDCl}_{3}\right) \delta 11.76,14.55,23.54,24.69,29.70,31.40$, $40.20,72.23,110.77,124.55,127.11,127.94,128.01,129.25,133.35,136.95,151.67 ; \mathrm{MS}(\mathrm{m} / \mathrm{z})$ $606\left(\mathrm{M}^{+}\right)$; Anal. Calcd for $\mathrm{C}_{38} \mathrm{H}_{48} \mathrm{Cl}_{2} \mathrm{O}_{2}$ : C, 75.10; H, 7.96. Found: C, 74.97; H, 8.07.

\subsubsection{1,4-Bis(2-ethylhexyloxy)-2,5-bis(p-cyanostyryl)benzene (1f)}

This compound was prepared in a manner similar to the procedure described above using 1,4-bis(2-ethylhexyloxy)-2,5-bis(diethylphosphonomethyl)benzene $\left(\begin{array}{llll}0.50 & \mathrm{~g}, & 0.79 \mathrm{mmol}) & \text { and }\end{array}\right.$ p-cyanobenzaldehyde $(0.21 \mathrm{~g} 1.6 \mathrm{mmol})$ and ${ }^{t} \mathrm{BuOK}(0.31 \mathrm{~g}, 2.8 \mathrm{mmol})$. Yield: 54\% (0.25 g) as light orange crystals; mp 160-161 ${ }^{\circ} \mathrm{C} ;{ }^{1} \mathrm{H}$ NMR $\left(400 \mathrm{MHz}, \mathrm{CDCl}_{3}\right) \delta 0.92\left(\mathrm{t}, 6 \mathrm{H},-\underline{\mathrm{C}}_{3}, J=7.0 \mathrm{~Hz}\right)$, $1.00\left(\mathrm{t}, 6 \mathrm{H},-\mathrm{C}_{3}, J=7.5 \mathrm{~Hz}\right), 1.30-1.64\left(\mathrm{~m}, 16 \mathrm{H},-\underline{\mathrm{C}}_{2}-\right), 1.76-1.89$ (m, 2H, >C- -), 3.97 (d, 4H, $\left.-\mathrm{OC}_{2_{2}}, J=5.5 \mathrm{~Hz}\right), 7.12(\mathrm{~s}, 2 \mathrm{H}, \mathrm{Ph}-\underline{\mathrm{H}}), 7.17$ (d, 2H, $\left.-\mathrm{CH}=\mathrm{C} \underline{\mathrm{H}}-, J=16.5 \mathrm{~Hz}\right), 7.52-7.68(\mathrm{~m}, 10 \mathrm{H}$, $-\mathrm{CH}=\mathrm{C} \underline{\mathrm{H}}-, \mathrm{Ph}-\underline{\mathrm{H}}) ;{ }^{13} \mathrm{C} \mathrm{NMR}\left(100 \mathrm{MHz}, \mathrm{CDCl}_{3}\right) \delta 11.74,14.52,23.51,24.69,29.67,31.38,40.14$, $72.18,110.79,119.51,127.12,127.20,127.50,127.72,132.90,142.82,151.93 ; \mathrm{MS}(\mathrm{m} / \mathrm{z}) 588\left(\mathrm{M}^{+}\right)$; Anal. Calcd for $\mathrm{C}_{40} \mathrm{H}_{48} \mathrm{~N}_{2} \mathrm{O}_{2}$ : C, 81.59; H, 8.22; N, 4.76. Found: C, 81.33; H, 8.35; N, 4.74.

\subsubsection{1,4-Bis(2-ethylhexyloxy)-2,5-bis(p-nitrostyryl)benzene (1g)}

This compound was prepared in a manner similar to the procedure described above using 1,4-bis(2-ethylhexyloxy)-2,5-bis(diethylphosphonomethyl)benzene $\left(\begin{array}{llll}0.50 & \mathrm{~g}, & 0.79 \mathrm{mmol}) & \text { and }\end{array}\right.$ p-nitrobenzaldehyde $(0.25 \mathrm{~g} 1.6 \mathrm{mmol})$ and ${ }^{t} \mathrm{BuOK}(0.31 \mathrm{~g}, 2.8 \mathrm{mmol})$. Yield: $24 \%(0.12 \mathrm{~g})$ as red crystals; mp 160-161 ${ }^{\circ}$; ${ }^{1} \mathrm{H}$ NMR $\left(400 \mathrm{MHz}, \mathrm{CDCl}_{3}\right) \delta 0.92\left(\mathrm{t}, 6 \mathrm{H},-\underline{\mathrm{H}}_{3}, J=7.0 \mathrm{~Hz}\right), 1.01$ (t, $6 \mathrm{H}$,

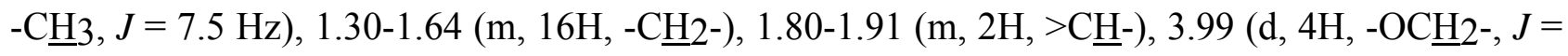

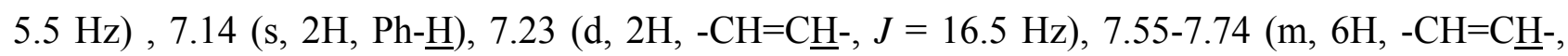
$\mathrm{Ph}-\underline{\mathrm{H}}$ ), 8.23 (d, 4H, Ph- $\underline{\mathrm{H}}, J=8.8 \mathrm{~Hz}) .{ }^{13} \mathrm{C} \mathrm{NMR}\left(100 \mathrm{MHz}, \mathrm{CDCl}_{3}\right) \delta 11.74,14.51,23.50,24.69$, 29.66, 31.38, 40.14, 72.18, 111.01, 124.60, 127.17, 127.21, 127.41, 128.40, 144.82, 147.07, 152.03; MS $(\mathrm{m} / \mathrm{z}) 628\left(\mathrm{M}^{+}\right)$. Although all spectra show the appropriate data for this compound, the satisfactory elemental analysis was not obtained. 


\subsection{Fluorescence quantum yields of the DSBs (1a-g)}

9,10-Diphenylanthracene was used as a standard $\left[\Phi_{\mathrm{F}}=1.00\right.$ in cyclohexane: Lit. G. Heinrich, S. Schoof, H. Gusten, J. Photochem. 3 (1974/75) 315-320)] by excitation at $375 \mathrm{~nm}$. All DSBs and 9,10-diphenylanthracene (DPA) were dissolved in cyclohexane at $10^{-6} \mathrm{M}$ and measured their absorptions at $375 \mathrm{~nm}$. Thus obtained absorptions (Abs) and the integrated areas (S) of the emission spectra obtained by excitation at $375 \mathrm{~nm}$ were used for estimation of the fluorescence quantum yields according to the following equation (a term for the index of refraction is omitted because of the measurements in the same solvent).

$$
\Phi_{\mathrm{F} \mathrm{DSB}} / \Phi_{\mathrm{F} D \mathrm{DP}}=\mathrm{S}_{\mathrm{DSB}} \times \mathrm{AbS}_{\mathrm{DPA}} / \mathrm{S}_{\mathrm{DPA}} \times \mathrm{Abs}_{\mathrm{DSB}}
$$

The relative fluorescence quantum yields in aqueous THF $\left(\mathrm{THF} / \mathrm{H}_{2} \mathrm{O}=3 / 1\right)$ were estimated in a manner similar to the above using $\mathbf{1 d}(\mathrm{R}=\mathrm{H})$ as a standard. These values are listed in Table 2 .

\section{3. $\quad$ Measurement of $\Phi_{C L}$}

For a typical run, $0.5 \mathrm{~mL}$ of a solution containing sodium carbonate $\left(4.0 \times 10^{-4} \mathrm{M}\right)$ and hydrogen peroxide $\left(1.0 \times 10^{-2} \mathrm{M}\right)$ in distilled water was added to $1.5 \mathrm{~mL}$ of a solution containing the oxalates $\left(5.0 \times 10^{-6} \mathrm{M}\right)$ and fluorophores $\left(1.0 \times 10^{-5} \mathrm{M}\right)$ in THF in a quartz cell placed in front of the photomultiplier at $25^{\circ} \mathrm{C}$. The photons generated were counted with the photomultiplier. The average of the values obtained by three times measurements was used for the calculation of $\Phi_{\mathrm{CL}}$.

\section{Results and discussion}

\subsection{Spectral data of distyrylbenzene (DSB) fluorophores}

DSB fluorophores 1a-g with 2-ethylhexyloxy groups at the center of the molecules for increasing their solubility in organic solvents and with various substituents at the para, para'-positions were prepared via the Horner-Wadsworth-Emmons reaction of the bisphosphonate and the corresponding aromatic aldehydes. The absorption and fluorescence spectra measured in aqueous THF are shown in Fig. 1, and the spectral data measured both in aqueous THF $\left(\mathrm{THF} / \mathrm{H}_{2} \mathrm{O}=3 / 1\right)$ and cyclohexane are summarized in Table 2. The Hammett substituent constants $\left(\sigma_{p}{ }^{+}\right)$of the DSBs are also included in Table 2. DSBs 1b-1e show absorption maxima around $390 \mathrm{~nm}$ and the emissions around $450 \mathrm{~nm}$, while 1a, 1f and $\mathbf{1 g}$ with strongly electron-donating or attracting substituents show some red-shifts 
in both spectra compared to the others. The fluorescence quantum yields $\left(\Phi_{\mathrm{F}}\right)$ of 1a-f in cyclohexane have similar values, and $1 \mathrm{~g}\left(\mathrm{R}=\mathrm{NO}_{2}\right)$ showed a much lower $\Phi_{\mathrm{F}}$ compared to the others. For CL study, the rel. $\Phi_{\mathrm{F}} \mathrm{S}$ in aqueous THF were also measured and $1 \mathrm{~g}$ was found to be almost non-fluorescent [42] probably due to the loss of the excitation energy through the hydrogen bonds of the nitro groups in protic media.

\subsection{DSB enhanced PO-CL reactions of the eight oxalates and the Hammett correlation between} the DSB substituents and the relative singlet chemiexcitation yields

When TCPO was reacted with alkaline hydrogen peroxide in the presence of $\mathbf{1 a}$ or $\mathbf{1 b}$ in aqueous THF, an intense CL was observed, whose spectra were in agreement with the fluorescence spectra of 1a and 1b (Fig. 2). This indicated that the emitting species are the excited 1a and $\mathbf{1 b}$ generated during the reactions as reported in the previous reports, in which the PO-CL reactions of the several oxalates and oxamates were enhanced by the various fluorescent DSBs in a bimolecular manner, and the CL quantum yields $\left(\Phi_{\mathrm{CL}}\right)$ were related to the electronic nature of the DSBs $[38,39]$.

All the PO-CL reactions using the oxalates listed in Table 1 were completed within a few seconds under the prescribed conditions for the present study and provided various total CL quantum yields $\left(\Phi_{\mathrm{CL}}\right)$ depending on the type of oxalates and fluorophores (Table 3$)$. Since the PO-CL reaction in the aqueous media is accompanied by hydrolysis of the oxalates to form the oxalic acids and phenols, a large excess amount of hydrogen peroxide (ca. 700 times vs. the oxalates) was used to undergo the peroxalate reactions before hydrolysis.

The $\Phi_{\mathrm{CL}}$ was highly dependent on the electronic nature of fluorophores in the previously investigated PO-CL reactions, and, therefore, a Hammett correlation between the $\Phi_{\mathrm{CL}}$ and the DSB substituent constants would give the useful information for the chemiexcitation of the DSBs as well as the information of the HEIs because the DSBs would electronically interact with the HEIs to form the polarized complexes initially as the precursors of the radical ion pairs according to the CIEEL mechanism. The relative singlet chemiexcitation yield (rel. $\Phi_{\mathrm{S}}$ defined as $\Phi_{\mathrm{CL}} / \mathrm{rel} . \Phi_{\mathrm{F}}$ ) for each CL reaction was correlated with the DSB substituent constants $\left(\sigma_{p}{ }^{+}\right)$in terms of the Hammett relationship; namely, the plots of $\sigma_{p}{ }^{+}$-values versus $\log \left(\Phi_{\mathrm{S}} / \Phi_{\mathrm{S}(\mathrm{H})}\right)$ for all the PO-CL reactions gave straight lines with negative slopes ( $\rho$-values) as shown in Fig. 3. The ${\sigma_{p}}^{+}$values were used as the substituent constants for the examination of the present Hammett correlation because the DSBs would interact with electron deficient HEIs to form the positively charged DSBs that would be stabilized with electron-donating substituents by the resonance effect. However, the DSB 1a and 1g could not be applied to the examination of this Hammett correlation because the former produced 
too high a $\Phi_{\mathrm{CL}}$ value that exceeded the limit of the photon-counting system set for this study and the latter was almost non-fluorescent under these CL conditions. It is interesting to note that the $\rho$-values for the eight oxalates in Table 4 are apparently classified into three groups by their ranges, i) the smallest value of -1.01 for DNPO, ii) between -0.9 and -0.8 for 2,4-DCPO, 2-CPO, 4-CPO, 4-CPPO and DPO, and iii) near -0.6 for TCPO and 2,6-DCPO. The salient feature of these $\rho$-values is that the highly activated DNPO had the highest absolute $\rho$-values, but two oxalates, TCPO and 2,6-DCPO, had the lowest values. Because the pKa values of the phenols $[43,44]$ are the tentative indicators of their electronic nature, the $\mathrm{pKa}$ of the phenols forming the oxalates (Table 1) are also related to the $\rho$-values as shown in Fig. 4 , in which the oxalates consisting of strongly acidic phenols tend to produce high absolute $\rho$-values except for TCPO and 2,6-DCPO.

The CL decay curves of the PO-CL enhanced by $\mathbf{1 b}$ as the representative fluorophore are shown in Fig. 5a and well fitted by the single exponential decay as shown in Fig. 5b as has been observed for the typical PO-CL $[12,13,45]$. The pseudo-first-order decay rate constants $(k)$ estimated from the logarithmic plots of the decay curves (Fig. 5b) are listed in Table 4. The rate-determining step for the formation of the HEIs will be the bimolecular process in which an oxalates reacts with perhydroxy anion to give hydroperoxide because the CL decay rates are dependent on the phenol acidity (Fig. 6) except for TCPO and 2,6-DCPO with much lower CL decay rates [22]. The observed correlation between $k$ and $\mathrm{pKa}$ is similar to that between $|\rho|$ and $\mathrm{pKa}$ (Fig. 4). The deviation for TCPO and 2,6-DCPO is probably due to the steric effect of the ortho-phenol substituents on the both initial and the subsequent intramolecular acyl substitutions to form the cyclic HEIs [45].

\subsection{Evaluation of the Hammett correlation providing various $\rho$-values and explanation by the} frontier molecular orbital (FMO) theory

As observed in the experimental results, various $\rho$-values with a relatively large range were produced depending on the oxalate structures, which suggests that the initial electronic interaction is a rate-limiting process for the chemiexcitation step and the reactive oxalates would give the polar species in the electronic interaction between the HEI and the DSBs. Since the electronic interaction is much faster than the chemical reactions forming the HEI and cannot be kinetically observed as has been documented $[3,6,14,17]$, the $\rho$-value will be related to the electronic interaction between the HEI and the fluorophores. For the high absolute $\rho$-value, the preferable electronic interaction would promote the electron exchange process to form a radical ion pair of the DSB radical cation and carbon dioxide radical anion in the CIEEL process. It should be noted that the formation of the excited DSBs is the result of the back electron transfer from the radical anions to the DSB radical 
cations, but the present study applying the Hammett correlation focuses on the initial stage of the electronic interaction between the HEIs and the DSBs, which, however, controls the DSB chemiexcitation as a result.

A possible explanation for various $\rho$-values in the Hammett correlation in the present PO-CL system is based on diversity of the HEIs electronically interacting with the DSBs; the oxalates with the higher $\rho$-values form HEIs which make effective electronic interactions. The strength of the electronic interactions depends on the oxalate structures, to indicate that HEIs retain the phenol moieties. Thus, DOD is excluded as a HEI. The DOT intermediates with the phenol ester moieties are, in principle, capable of generating excited fluorophores by an electronic interaction with the fluorophores [19] considering the structural similarity to the chemiluminescent $\alpha$-peroxy lactones [46]. The same $\rho$-value for DPO and 4-CPPO is probably due to the structurally same HEIs, because 4-CPPO would eliminate the 4-chlolophenol by the initial nucleophilic acyl substitution leading to the formation of an intermediate the same as that formed from DPO.

The relative heats of formation of the phenyl $O, O$-hydrogen monoperoxalate, the HEIs, such as the DOT together with DOD, and the final products, such as carbon dioxide and phenol, calculated by $a b$ initio method using the B3LYP/6-31G (d) basis set, are shown in Fig. 7 as examples. The formation of the cyclic peroxides, the HEIs from the acyclic hydroperoxide, is an endothermic process, while their decomposition to carbon dioxide and phenol is a very favorable exothermic process. It is noteworthy that the conversion from the DOT to the DOD is an endothermic process with a small energy difference $(4.64 \mathrm{kcal} / \mathrm{mol})$, which slightly favors the DOT at equilibrium, and the DOT can be a candidate for the HEI more than DOD.

The Hammett substituent constants are also regarded as the index of the electron releasing ability and parallel to the oxidation potentials of the compounds bearing the Hammett substituents. Therefore, the Hammett relationship has been applied to explain the substituent effect on the electron transfer [47-50]. The Hammett correlation also has been rationalized with the FMO theory [51], in which the magnitudes of the $\rho$-values are closely related to the energy gaps between the HOMOs and LUMOs of the electron-donor and electron-acceptor, respectively. When two molecular orbitals interact, the smaller the interval between the FMO energies, the higher the interaction energy becomes. The small difference in the energy gap of the FMOs leads to increase contribution of the electronic effect on the reaction process, resulting in the higher $\rho$-values. This treatment with the FMO theory for the electronic interaction between the HEI and the DSBs corresponds to the analysis with CIEEL mechanism. As the negative sign of the $\rho$-values in the present PO-CL system indicates the interaction of the DSB-HOMOs and DOT- or DOD-LUMOs, the FMO theory predicts that the lower LUMO energies of DOT leads to the smaller energy difference between their LUMOs and the DSB-HOMOs in the endothermic electron transfer, 
resulting in the significant change in the electronic interaction rates along with the changes in the $\sigma_{p}{ }^{+}$-values, and finally increasing the absolute $\rho$-values.

The energies of the DSB-HOMOs and the DOT-LUMOs as well as the DOD-LUMO were also calculated and their energy levels and the representative orbital shapes are shown in Fig. 8. For the DOT produced from DNPO, the LUMO+2 was selected as the orbital interacting with the DSBs because its LUMO and LUMO+1 are localized at the phenyl ring bearing two nitro groups. For all the DOTs (LUMO+2 for the DOT from DNPO), the LUMOs extend on the O-O bondings, which is reasonable for the proposed CIEEL process that begins with an electron transfer from the fluorophores to the anti-bonding orbitals of the DOTs. There is a remarkable difference in the shapes of the LUMOs of the DOTs and DOD, the former of which is anti-bonding but the latter of which is bonding, but both HEIs are ready to accept an electron as revealed by the extending LUMOs on the O-O bondings. If both HEIs hold an electron to form their radical anions, the O-O bond cleavage will readily take place. Fig. 9 shows the relationship between the $\rho$-values and the LUMO energies of the DOTs, in which the oxalates with the higher absolute $\rho$-values tend to have lower LUMO energies except for TCPO and 2,6-DCPO. This tendency agrees with the prediction by the FMO theory, if the DOT is involved in the electronic interaction during the CIEEL process. On the other hand, the deviation by TCPO and 2,6-DCPO is also significant because they would give much higher $\rho$-values from the viewpoint of the FMO theory conflicting with the experimental observation. The steric hindrance in the HEIs would not only decrease the CL decay rate but also restrain the electronic interactions with the DSBs, which also correlates with the importance of the DOTs as the HEIs because such results would be expected for the aryl group containing HEIs. When the DOTs electronically interact with the fluorophores, it would be possible that the DOT radical anions decompose into phenols and $\mathrm{CO}_{2}$ including its radical anions because the $\sigma *$ bonding of the DOT occupied with an electron readily breaks resulting in a ring cleavage as shown in Scheme 2 .

\section{Conclusions}

In the present PO-CL reactions using several oxalates and the DSB fluorophores, the linear Hammett correlations with various $\rho$-values between the singlet chemiexcitation yields and the DSB substituent constants $\left(\sigma_{p}{ }^{+}\right)$were established, and the $\rho$-values were related to the CL decay rates and LUMO energies of the postulated HEIs such as the DOTs. The FMO theory explains the experimental observations by the reason that the electronic interaction operates with various biases depending on the oxalate structure and that the donor-acceptor electronic interaction determines the 
$\rho$-value.

\section{Acknowledgements}

This work was supported by the Global COE from the Ministry of Education, Culture, Sports, Science and Technology of Japan.

\section{References}

[1] E.A. Chandross, A new chemiluminescence system, Tetrahedron Lett. (1963) 761-765.

[2] M.M. Rauhut, D. Sheehan, R.A. Clarke, A.M. Semsel, Structural criteria for chemiluminescence in acyl peroxide decomposition reactions, Photochem. Photobiol. 4 (1965) 1097-1110.

[3] M.M. Rauhut, Chemiluminescence from concerted peroxide decomposition reactions, Acc. Chem. Res. 2(1969) 80-87.

[4] P. Lechtken, N.J. Turro, Peroxyoxalate chemiluminescence. Chemiexcitation of high-energy excited states in acceptor molecules, Mol. Photochem. 6 (1974) 95-99.

[5] C.L.R. Catherall, T.F. Palmer, R.B. Cundall, Chemiluminescence from reactions of bis(pentachlorophenyl)oxalate, hydrogen peroxide and fluorescent compounds, kinetics and mechanism, J. Chem. Soc. Faraday Trans. 2 80(1984) 823-836.

[6] C.L.R. Catherall, T.F. Palmer, R.B. Cundall, Chemiluminescence from reactions of bis(pentachlorophenyl) oxalate, hydrogen peroxide and fluorescent compounds, role of the fluor and nature of chemielectron process, J. Chem. Soc. Faraday Trans. 280 (1984) 837-849.

[7] J.H. Lee, J.C. Rock, S.B. Park, M. A. Schlautman, E.R. Carraway, Study of the characteristics of three high-energy intermediates generated in peroxyoxalate chemiluminescence (PO-CL) reactions, J. Chem. Soc. Perkin Trans. 2 (2002) 802-809.

[8] J.H. Lee, J.C. Rock, M.A. Schlautman, E.R. Carraway, Characteristics of key intermediates generated in uncatalyzed bis(2,4-dinitrophenyl) oxalate (DNPO) chemiluminescence reactions, J. Chem. Soc. Perkin Trans. 2 (2002) 1653-1657.

[9] J.H. Lee, J. Je, M.A. Schlautman, E.R. Carraway, Fast peroxyoxalate chemiluminescence for minimized analytical separation systems, Chem. Comm. (2003) 270-271.

[10] P.S. Park, T.-H.D. Rho, Y.T. Kim, S.O. Ko, M.A. Schlautman, E.R. Carraway, J.H. Lee, Evidence of multiple pathways capable of emitting peroxyoxalate chemiluminescence using a charge coupled device spectrometer, Chem. Comm. 47 (2011) 5542-5544.

[11] F. J. Alvarez, N. J. Perekh, B. Matuszewski, R.S. Givens, T. Higuchi, R.L. Schowen, Multiple intermediates generate fluorophore-derived light in the oxalate/peroxide chemiluminescence system, J. Am. Chem. Soc. 108 (1986) 6435-6437. 
[12] M. Orlovic, R.L. Schowen, R.S. Givens, F. Alvarez, B. Matuszewski, N. Parekh, A simplified model for the dynamics of chemiluminescence in the oxalate-hydrogen peroxide system: toward a reaction mechanism, J. Org. Chem. 54 (1989) 3606-3610.

[13] G. Orosz, R.S. Givens, R.L. Schowen, Chemiluminescence arising from the interaction of rubrene with intermediates derived from hydrogen peroxide and bis(2,4-dinitrophenyl) oxalate (DNPO): quantum yield and carbondioxide yield, Anal. Chim. Acta. 266 (1992) 219-223.

[14] C.V. Stevani, D.F. Lima, V.G. Toscano, W.J. Baader, Kinetic studies on the peroxyoxalate chemiluminescenct reaction: imidazole as a nucleophilic catalyst, J. Chem. Soc. Perkin Trans. 2 (1996) 989-995.

[15] C.S. Stevani, I.P. de A. Campos, W.J. Baader, Synthesis and characterization of an intermediate in the peroxyoxalate chemiluminescence: 4-chlorophenyl O,O-hydrogen monoperoxyoxalate, J. Chem. Soc. Perkin Trans. 2 (1996) 1645-1648.

[16] R.E. Milofsky, J.W. Birks, Photoinitiation of peroxyoxalate chemiluminescence: application to flow injection analysis of chemilumophores, Anal. Chem. 62 (1990) 1050-1055.

[17] R.E. Milofsky, J.W. Birks, Laser photolysis study of the kinetics and mechanism of photoinitiated peroxyoxalate chemiluminescence, J. Am. Chem. Soc. 113 (1991) 9715-9723.

[18] A.G. Hadd, A.L. Robinson, K.L. Rowlen, J.W. Birks, Stopped-flow kinetics investigation of the imidazole-catalyzed peroxyoxalate chemiluminescence reaction, J. Org. Chem. 63 (1998) 3023-3031.

[19] A.G. Hadd, A. Seeber, J. W. Birks, Kinetics of two pathways in peroxyoxalate chemiluminescence, J. Org. Chem. 65 (2000) 2675-2683.

[20] T. Jonsson, K. Irgum, Very fast peroxyoxalate chemiluminescence, Anal. Chim. Acta 400 (1999) 257-264.

[21] R. Koike, J. Motoyoshiya, Y. Takaguchi, H. Aoyama, The key intermediates that interact with the fluorophores in the peroxyoxalate chemiluminescence reaction of 2,4,6-trichlorophenyl-N-aryl-N-tosyloxamates, Chem. Comm. (2003) 794-795.

[22] G. Orosz, The role of diaryl oxalates in peroxyoxalate chemiluminescence, Tetrahedron Lett. 45 (1989) 3493-3506.

[23] C.L.R. Catherall, T.F. Palmer, R.B. Cundall, Determination of absolute chemiluminescence quantum yields for reactions of bis(pentachlorophenyl) oxalate, hydrogen peroxide and fluorescent compounds, J. Biolumin. Chemilumin. 3 (1989) 147-154.

[24] H.P. Chokshi, M. Barbush, R.G. Carlson, R.S. Givens, T. Kuwana, R.L. Schowen, Oxalate/hydrogen peroxide chemiluminescence reaction. ${ }^{19} \mathrm{~F}$ probe of the reaction mechanism, Biomed. Chromat. 4 (1990) 96-99.

[25] C. Gooijier, P. van Zoonen, N.H. Velthorst, R.W. Frei, On the mechanism of peroxyoxalate 
chemiluminescence. Quenched chemiluminescence as a detection method in HPLC, J. Biolumin. Chemilumin. 4 (1989) 479-483.

[26] M. Tsunoda, K. Imai, Analytical applications of peroxyoxalate chemiluminescence, Anal. Chem. Acta 541 (2005) 12-23.

[27] A.M. Garcia-Campana, F.J. Lara, Trend in the analytical applications of chemiluminescence in the liquid phase, Anal. Bioanal. Chem. 387 (2007) 165-169.

[28] R. Bos, N.W. Barnett, G.A. Dyson, K.F. Lim, R.A. Russel, S.P. Watson, Studies on the mechanism of the peroxyoxalate chemiluminescence reaction Part 1. Confirmation of 1,2-dioxetanwdione as an intermediate using ${ }^{13} \mathrm{C}$ nuclear magnetic resonance spectroscopy, Anal. Chim. Acta 502 (2004) 141-147.

[29] S.A. Tonkin, R. Bos, G.A. Dyson, K.F. Lim, R.A. Russell, S.P. Watson, C.M. Hindson, N.W. Barnett, Studies on the mechanism of the peroxyoxalate chemiluminescence reaction: part 2. Further identification of intermediates using $2 \mathrm{DeXSY}{ }^{13} \mathrm{C}$ nuclear magnetic resonance spectroscopy, Anal. Chim. Acta 614 (2008) 173-181.

[30] R. Bos, S.A. Tonkin, G.R. Hanson, C.M. Hindson, K.F. Lim, N.W. Barnett, In search of a chemiluminescence 1,4-dioxy biradical, J. Am. Chem. Soc. 131 (2009) 2770-2771.

[31] G.B. Schuster, Chemiluminescence of organic peroxides. Conversion of ground-state reactions to excited products by the chemically initiated electron-exchange luminescence mechanism, Ac. Chem. Res. 12 (1979) 366-373.

[32] T. Wilson, Comments on the mechanism of chemi- and bioluminescence, Photochem. photobiol. 62 (1995) 601-606.

[33] F. McCapra, K. Perring, R.J. Hart, R.A. Hann, Photochemistry without light - Reaction of active oxalate esters with anthracenophanes, Tetrahedron Lett. 22 (1981) 5087-5090.

[34] C.V. Stevani, S.M. Silva, W.J. Baader, Studies on the mechanism of the excitation step in peroxyoxalate chemiluminescence, J. Eur. J. Org. Chem. (2000) 4037-4046.

[35] S.M. Silva, F.C. Casallanovo Jr., K.H. Oyamaguchi, L.F.L.M. Cisato, C.V. Stevani, W.J. Baader, Kinetic studies on the peroxyoxalate chemiluminescence reaction: determination of the cyclization rate constant, Lumin. 17 (2002) 313-3235.

[36] S.M. Silva, K. Wagner, D. Weiss, R. Beckert, C.V. Stevani, W.J. Baader, Studies on the chemiexcitation step in peroxyoxalate chemiluminescence using steroid-substituted activators, Lumin. 17 (2002) 362-369.

[37] L.F.M.L. Ciscato, F.H. Bartoloni, E.L. Bastos, W.J. Baader, Direct kinetic observation of the chemiexcitation step in peroxyoxalate chemiluminescence, J. Org. Chem. 74 (2009) 8974-8979.

[38] J. Motoyoshiya, N. Sakai, M. Imai, Y. Yamaguchi, R. Koike, Y. Takaguchi, H. Aoyama, Peroxyoxalate chemiluminescence of $N, N^{\prime}$-bistosyl-1H,4H-quinoxaline-2,3-dione and related 
compounds. Dependence on electronic nature of fluorophores, J. Org. Chem. 67 (2002) 7314-7318.

[39] R. Koike, Y. Kato, J. Motoyoshiya, Y. Nishii, H. Aoyama, Unprecedented chemiluminescence behaviour during peroxyoxalate chemiluminescence of oxalates with fluorescent or electron-donating aryloxy groups, Lumin. 21 (2006) 164-173.

[40] T. Maruyama, Y. Fujie, N. Oya, E. Hosaka, A. Kanazawa, D. Tanaka, Y. Hattori, J. Motoyoshiya, Control of peroxyoxalate chemiluminescence by nitrogen-containing ligand quenching: turning off and on by ligand-metal ion host-guest interactions, Tetrahedron 67 (2011) 6927-6933.

[41] A. Heller, Organic liquid scintillators. VI. Substituted distyrylbenzenes: scintillation properties and spectra of absorption and fluorescence, J. Chem. Phys. 40 (1964) 2839-2851.

[42] S. Nakatsuji, K. Matsuda, Y. Uesugi, K. Nakashima, S. Akiyama, G. Katzer, W. Fabian, Synthesis and absorption/emission spectral propeerties of styrylstilbene and distyrylanthracene derivatives, J. Chem. Soc. Perkin Trans. 2 (1991) 861-867.

[43] J. Han, R.L. Deming, F.-M. Tao, Theoretical study of hydrogen-bonded complexes of chlorophenols with water or ammonia: correlatoions and predictions of $\mathrm{pKa}$ values, J. Phys. Chem. A 109 (2005) 1159-1167.

[44] E.S. Swann, C.J. Moody, M.R.L. Staratford, K.B. Patel, M.A. Naylor, B. Vojnovic, P. Wardman, S.A. Everett, Rates of reductive elimination of substituted nitrophenols frpm the (indo-3-yl)methyl position of indolequinones, J. Chem. Soc. Perkin Trans 2 (2001) 1340-1345.

[45] M. Shamsipur, K. Zargoosh, M.J. Chaichi, M. Tajbakhsh, A. Parach, Peroxyoxalate-chemiluminescence of Tinopal CBS as a commercially important optical brightener: Mechanistic study and quantification, J. Lumninescence 130 (2010) 748-755.

[46] W. Adam, J.-C. Liu, An a-peroxylactone. Synthesis and chemiluminescence, J. Am. Chem. Soc. 94 (1972) 2894-2895.

[47] S. Komamine, M. Fujitsuka, O. Itoh, Photoinduced electron transfer of $\mathrm{C}_{60}$ and p-substituted anilines, Phys. Chem. Chem. Phys. 1 (1999) 4745-4749.

[48] M.A. Prasad, M.V, Sangaranarayanan, Linear kinetic and free energy correlations for intramolecular dissociative electron-transfers-Estimation of standard potentials and cleavage rate constants of radical anions of aromatic halides, Chem. Phys. Lett. 421 (2006) 193-197.

[49] T. M. Krygowski, N. Sadlej-Sosnowska, Towards physical interpretation of Hammett constants: charge transferred between active regions of substituents and a functional group, Struc. Chem. 22 (2011) 17-22.

[50] L.F.M.L. Cisato, F.H. Bartoloni, D. Weiss, R. Beckert, W.J. Baader, Experimetal evidence of the occurrence of intramolecular electron transfer in catalyzed 1,2-diexwtane decomposition, J. 
Org. Chem. 75 (2010) 6574.

[51] O. Henri-Rousseau, F. Texier, Application of the frontier molecular orbital theory to the interpretation of the Hammett correlations, J. Chem. Edu. 55 (1978) 437-441.

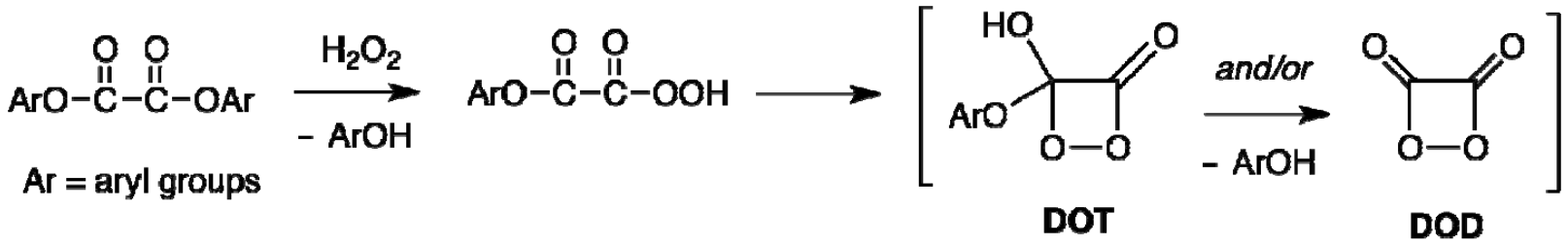

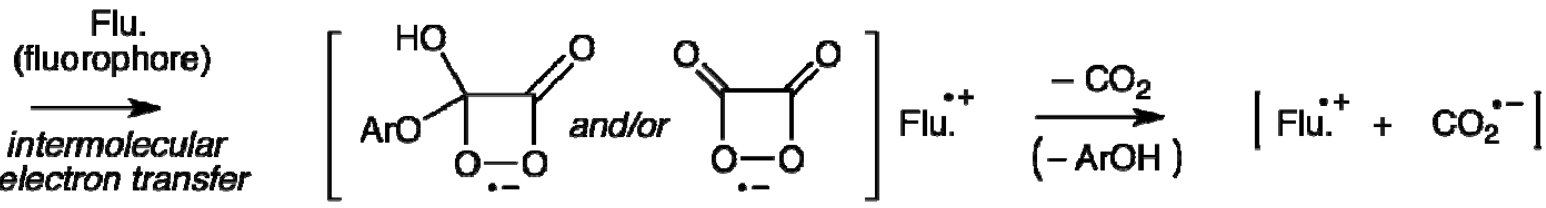

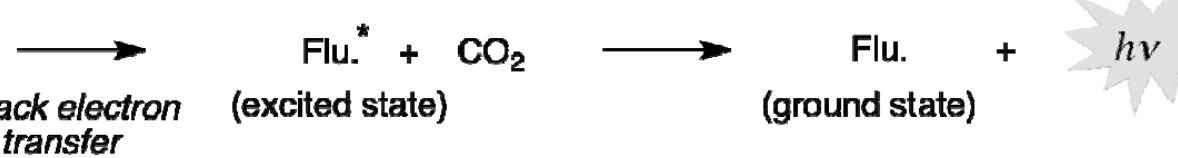

Scheme 1. A CIEEL process of peroxyoxalate chemiluminescence containing the diexetanones (DOTs) or dioxetanedione (DOD) high-energy intermediates.

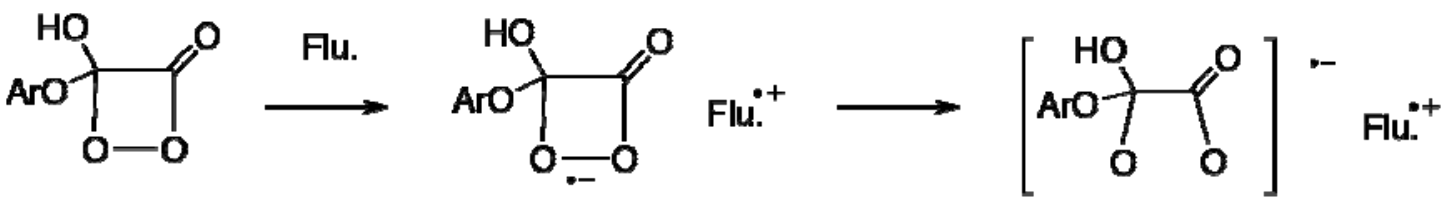

$\longrightarrow \mathrm{CO}_{2}^{*-}+\mathrm{Flu}^{*+}+\mathrm{ArOH}+\mathrm{CO}_{2} \longrightarrow \mathrm{Flu}^{*}+\mathrm{ArOH}+2 \mathrm{CO}_{2}$

Scheme 2. A plausible CIEEL path involving the DOTs as the electron acceptors. 
(a)

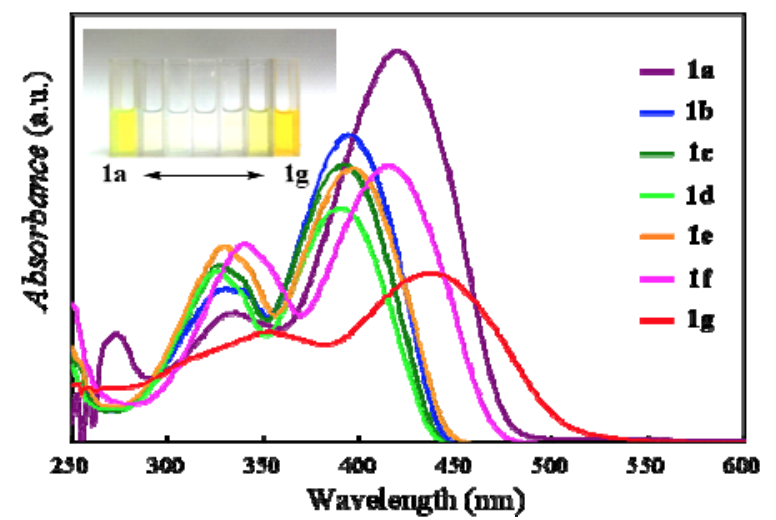

(b)

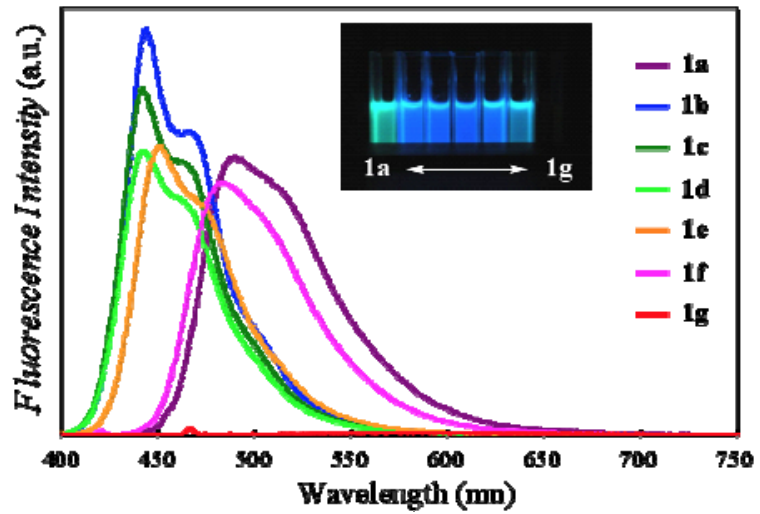

Fig. 1. Absorption (a) and fluorescence (b) spectra of the DSBs 1a-g. $7.5 \times 10^{-6} \mathrm{M}$ in $\mathrm{THF} / \mathrm{H}_{2} \mathrm{O}(3: 1)$.

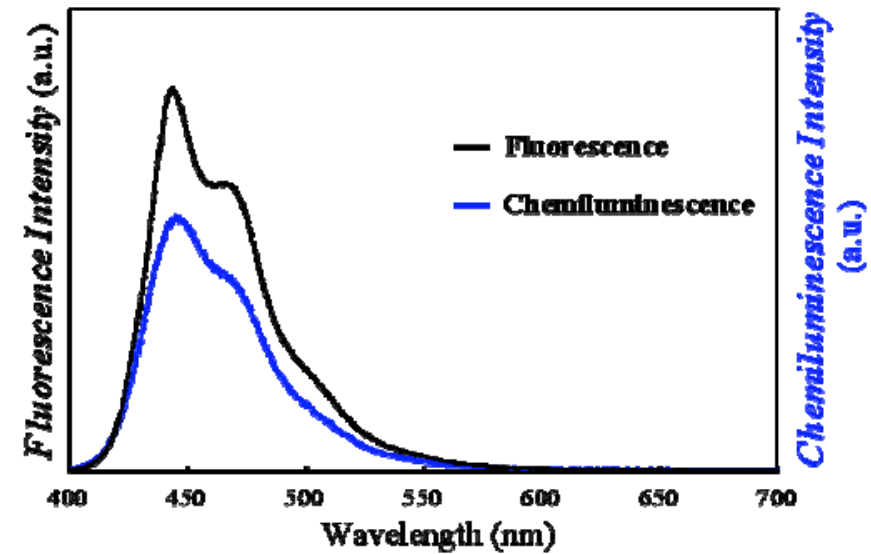

Fig. 2. Fluorescence and chemiluminescence spectra of $\mathbf{1 b}$ using TCPO. Oxalate $\left(7.5 \times 10^{-5} \mathrm{M}\right)$, DSB derivatives $\left(7.5 \times 10^{-6} \mathrm{M}\right)$ and $\mathrm{H} 2 \mathrm{O} 2\left(2.5 \times 10^{-1} \mathrm{M}\right)$ in $\mathrm{THF} / \mathrm{H}_{2} \mathrm{O}(3: 1)$ were used. 

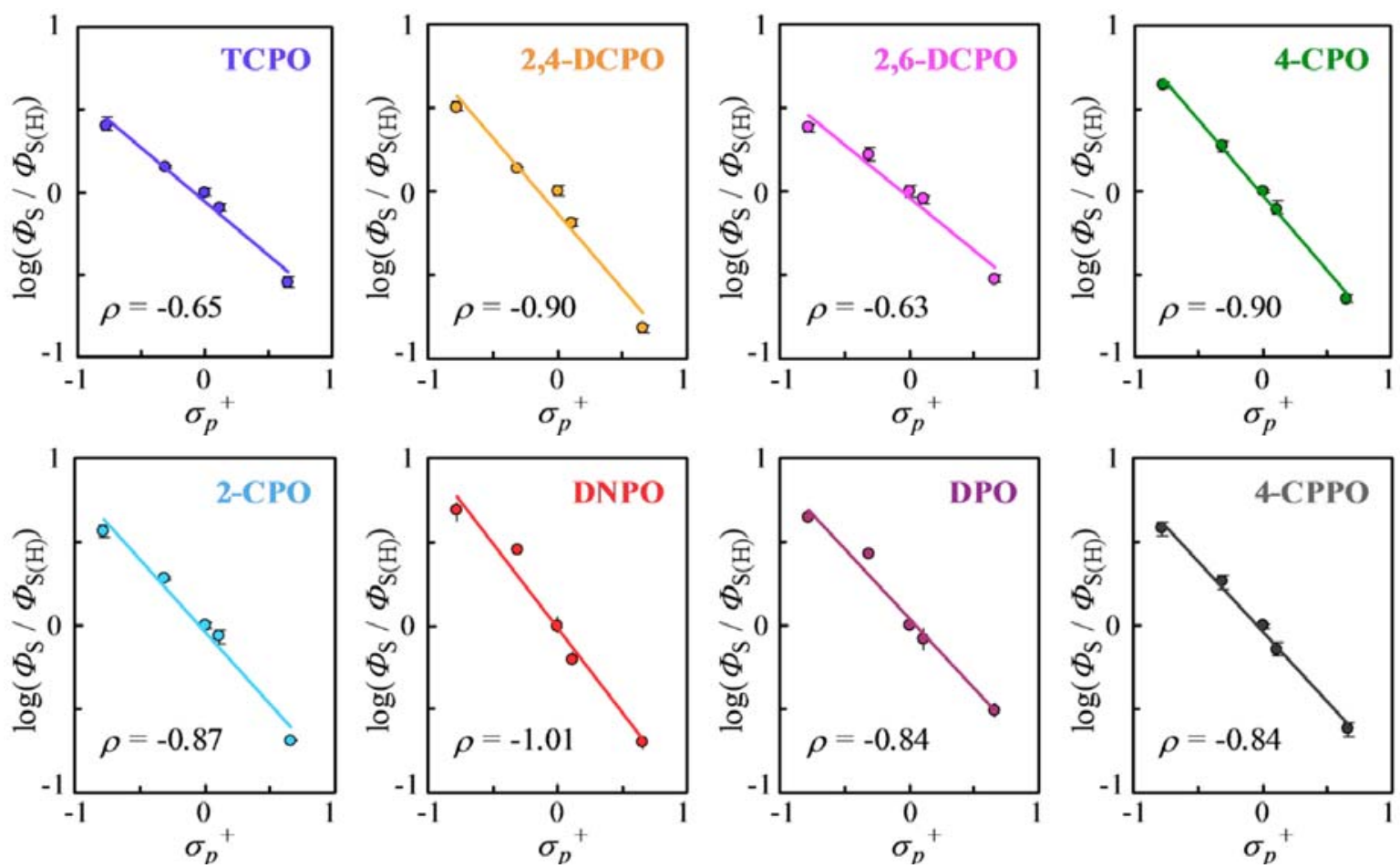

Fig. 3. The Hammett correlation of PO-CL of the eight oxalates enhanced by DSBs (1b-f). [oxalates $]=3.75 \times 10^{-6} \mathrm{M},[\mathrm{DSBs}]=7.5 \times 10^{-6} \mathrm{M},\left[\mathrm{H}_{2} \mathrm{O}_{2}\right]=2.5 \times 10^{-3} \mathrm{M}$, and $\left[\mathrm{Na}_{2} \mathrm{CO}_{3}\right]=7.5 \times 10^{-5} \mathrm{M}$ in $\mathrm{THF} / \mathrm{H}_{2} \mathrm{O}(3 / 1)$.

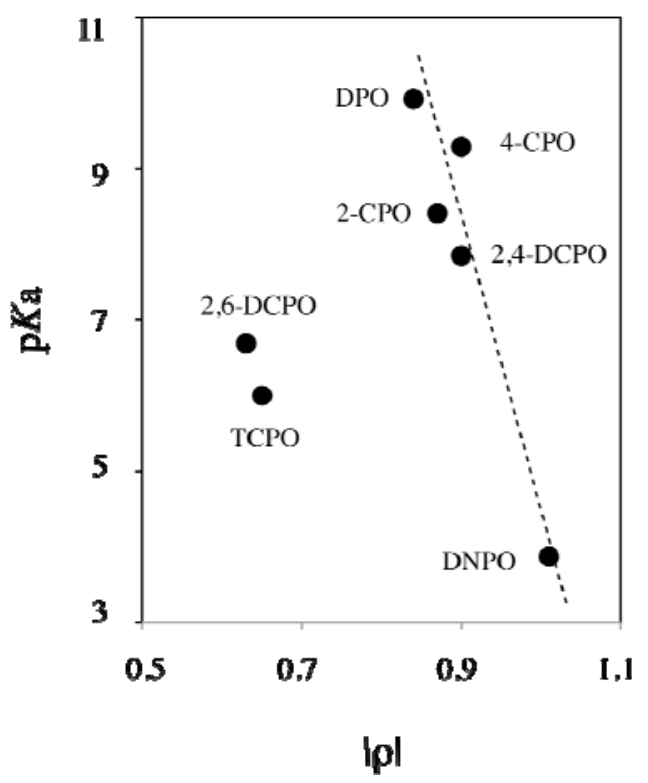

Fig. 4. Correlation of $\mathrm{pKa}$ of phenols in the oxalates and $\rho$-values. 
(a)

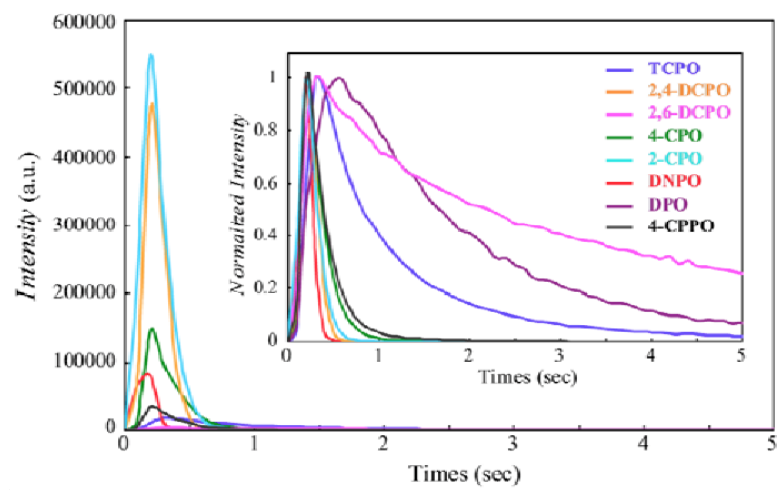

(b)

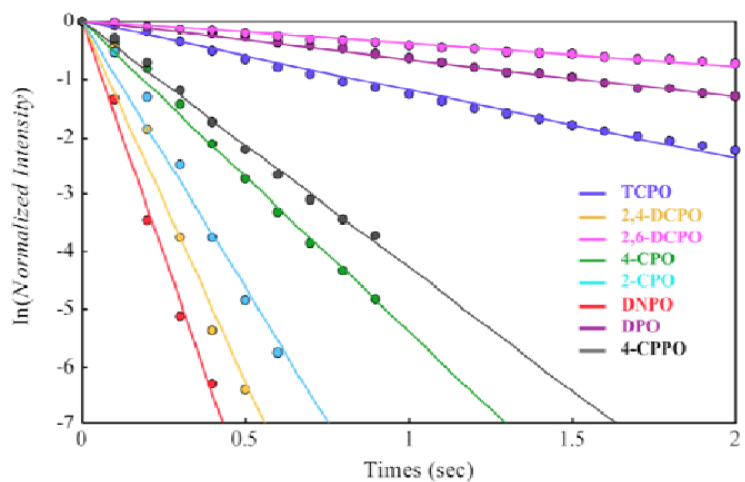

Fig. 5. The CL decay curves and logarithm plots of the eight oxalates using $\mathbf{1 b}$ as the fluorophore: (a) CL decy curves (inset: normalized curves), (b) pseudo-first-order reaction fitting of the normalized CL emission decays. [oxalate] $=3.75 \times 10^{-6} \mathrm{M},[\mathbf{1 b}]=7.5 \times 10^{-6} \mathrm{M},\left[\mathrm{H}_{2} \mathrm{O}_{2}\right]=2.5 \times 10^{-3} \mathrm{M}$, and $\left[\mathrm{Na}_{2} \mathrm{CO}_{3}\right]=7.5 \times 10^{-5} \mathrm{M}$ in THF/ $\mathrm{H}_{2} \mathrm{O}(3 / 1)$. Standard deviations $\left(\mathrm{R}^{2}\right): 0.990$ for TCPO, 0.995 for 2,4-DCPO), 0.979 for 2,6-DCPO, 0.994 for 4-CPO, 0.979 for 2-CPO, 0.992 for DNPO, 0.996 for DPO, 0.994 for 4-CPPO.

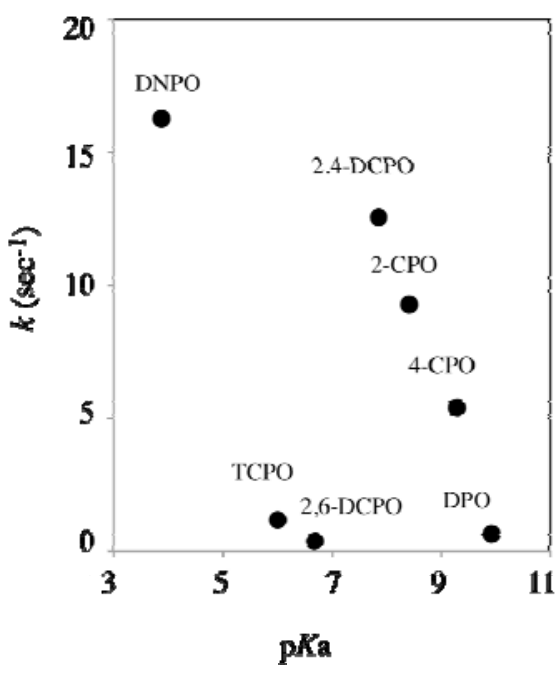

Fig. 6. Correlation of the CL decay rates $(k)$ and $\mathrm{pKa}$ of phenols in the oxalates. 


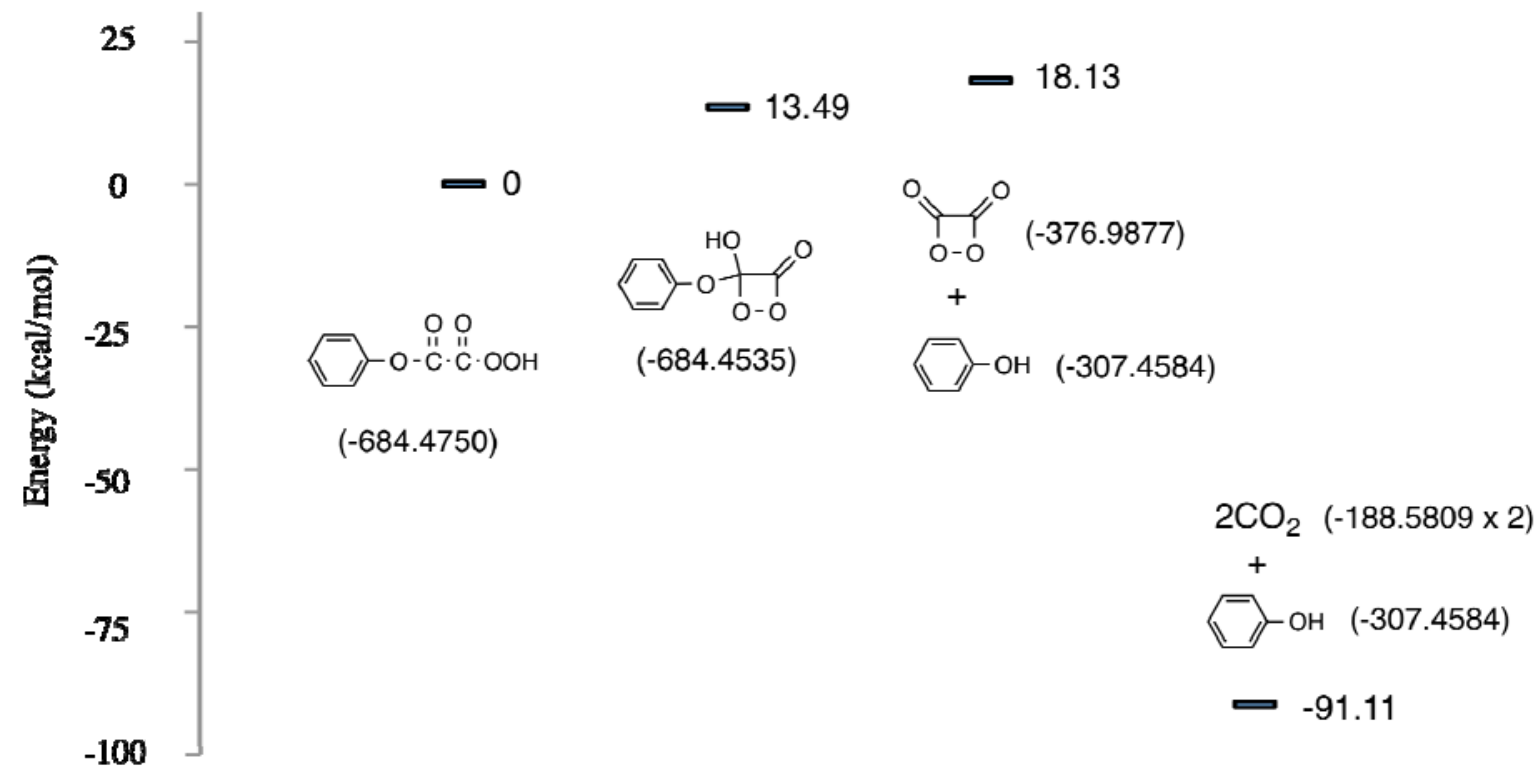

Fig. 7. Relative heats of the formation of the high-energy intermediates and its decomposition. The values in parentheses are the energies in atomic unit (Hartree) calculated by the $a b$ initio method with a B3LYP/6-31g(d) basis set. 


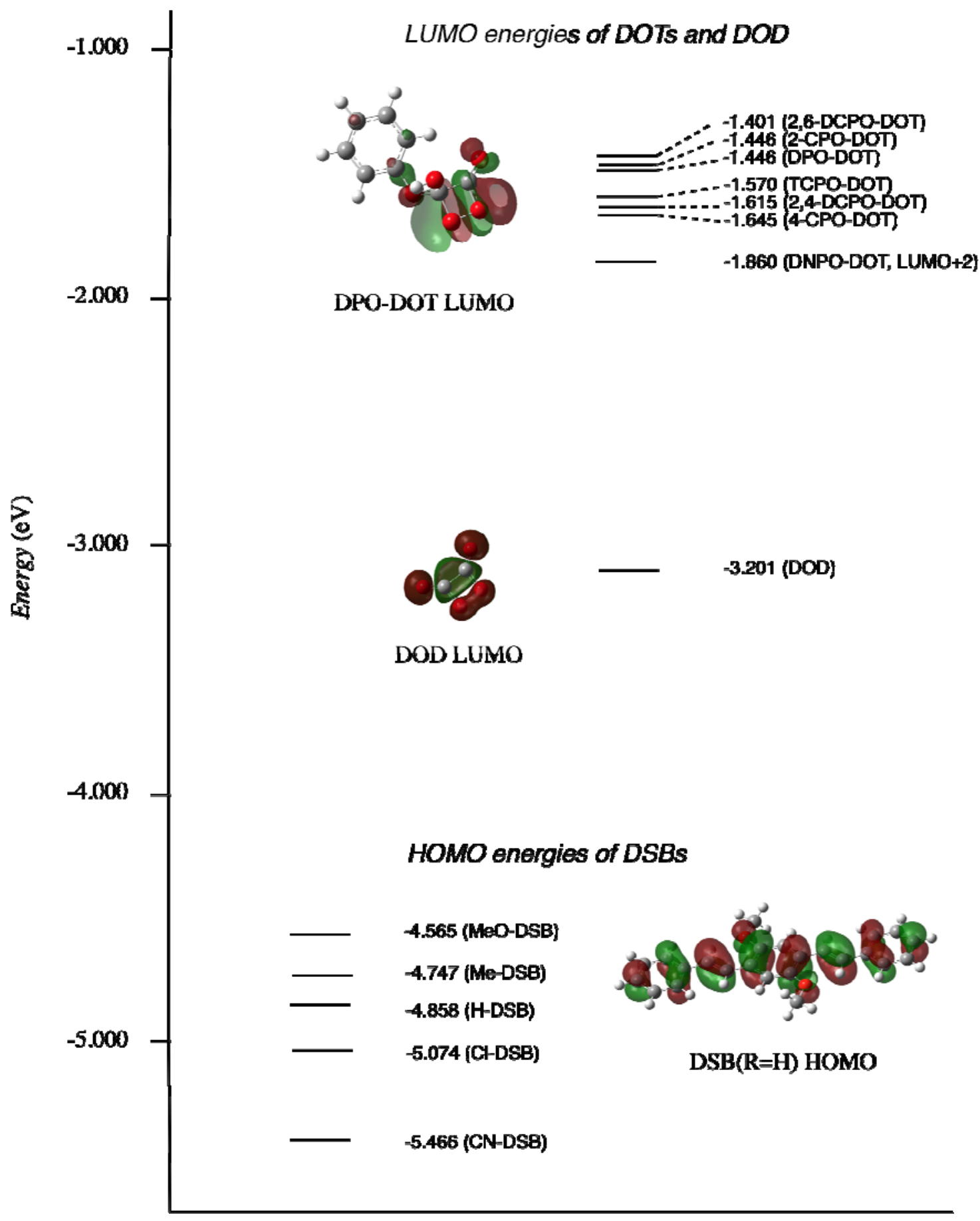

Fig. 8. The HOMO (DSBs) and LUMO (DOTs and DOD) energies. Calculated by the $a b$ initio method with a B3LYP/6-31g(d) basis set. 


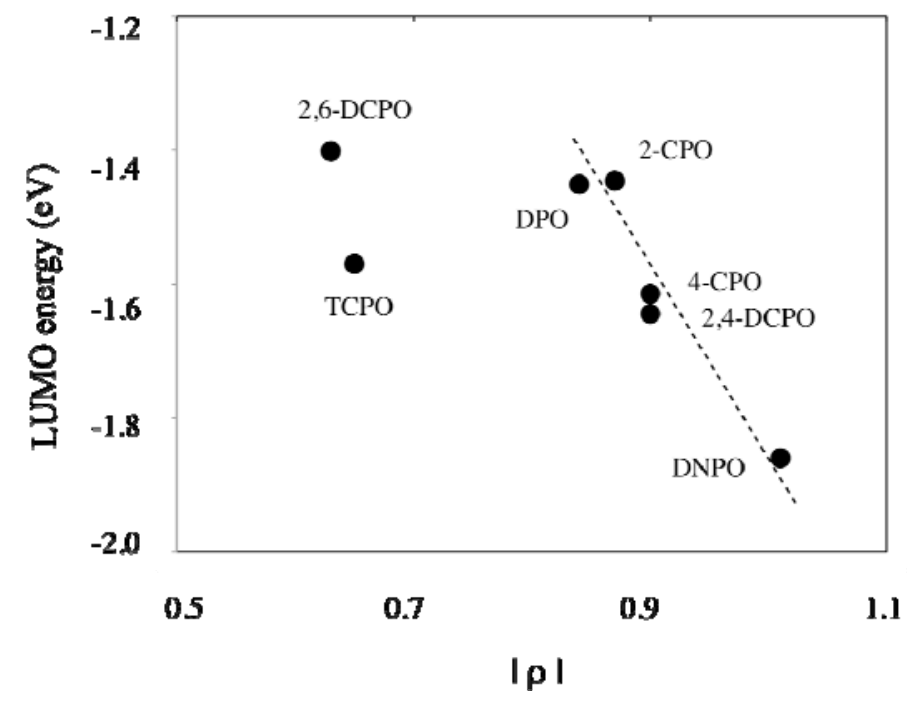

Fig. 9. Plots of absolute $\rho$-value vs. LUMO energy. 


\section{Table 1}

Structures of oxalates used in this study and $\mathrm{pKa}$ of phenols as leaving groups.

\begin{tabular}{|c|c|c|c|c|c|}
\hline Oxalate & Abbreviation & $\mathbf{x}_{1}$ & $\mathbf{x}_{2}$ & $\mathbf{x}_{3}$ & $\mathrm{pKa}$ of phenol \\
\hline diphenyl oxalste & DPO & H & H & H & 9.91 \\
\hline bis(2,4,6-tricholorophenyl) oxalate & TCPO & $\mathbf{C l}$ & $\mathbf{C I}$ & CI & 6.00 \\
\hline bis(2,4-dichlomphenyl) axalgie & 2,4-DCPO & $\mathbf{C l}$ & $\mathbf{C I}$ & H & 7.85 \\
\hline his(2,6-dichlorophenyl) oxalste & 2,6-DCPO & $\mathbf{C l}$ & $\mathbf{H}$ & $\mathbf{C l}$ & 6.69 \\
\hline bis(4-chlorophenyl) axalate & 4-CPO & 吾 & $\mathbf{C l}$ & H & 9.29 \\
\hline bis(2-chlorophenyl) axalste & 2-CPO & $\mathbf{C l}$ & $\mathbf{H}$ & H & 8.41 \\
\hline bis(2,4-dinitrophenyl) oxalate & DNPO & $\mathrm{NO}_{2}$ & $\mathrm{NO}_{2}$ & $\mathbf{H}$ & 3.87 \\
\hline 4-chlorophenyl phenyl oxalate & 4CPPO & & & & - \\
\hline
\end{tabular}

Table 2

The Hammett substituent constants $\left(\sigma_{p}{ }^{+}\right)$and spectral data of distyrylbenzenes (DSBs). ${ }^{\text {a }}$

\begin{tabular}{|c|c|c|c|c|c|c|}
\hline DSBs & $\mathbf{R}$ & $\boldsymbol{\sigma}_{\boldsymbol{p}}^{+}$ & $\lambda_{\operatorname{mas}}(\mathrm{nm})^{a}$ & $\lambda_{\operatorname{man}}(\mathrm{nm})$ & $\boldsymbol{\Phi}_{\mathrm{F}}^{b}$ & rel. $\phi_{\mathrm{p}}$ in aq. THF ${ }^{\propto e}$ \\
\hline $\mathbf{I a}$ & $\mathrm{NMr}_{2}$ & -1.70 & 419 & $490(441)$ & 0.73 & 1.32 \\
\hline $\mathbf{l b}$ & $\mathrm{OMe}$ & -0.778 & 394 & 444(395) & 0.78 & 1.32 \\
\hline le & $\mathbf{M e}$ & -0.311 & 391 & $442(340)$ & 0.75 & 1.16 \\
\hline 1d & H & 0 & 390 & $442(390)$ & 0.76 & 1.00 \\
\hline $1 e$ & $\mathrm{Cl}$ & 0.114 & 396 & $451(397)$ & 0.81 & 1.03 \\
\hline 1f & $\mathrm{CN}$ & 0.659 & 415 & $484(424)$ & 0.70 & 1.10 \\
\hline Ig & $\mathrm{NO}_{2}$ & 0.790 & 444 & $556(452)$ & 0.25 & 0.04 \\
\hline
\end{tabular}

$a$ Measured in $\mathrm{THF} / \mathrm{H}_{2} \mathrm{O} \quad(3 / 1)\left(7.5 \times 10^{-6} \quad \mathrm{M}\right) .^{b}$ Measured in cyclohexane using 9,10-diphenylanthracene as a standard. ${ }^{c}$ Relative values based on the $\Phi_{\mathrm{F}}$ for $\mathbf{1 d}$. 
Table 3 Chemiluminescence quantum yields $\left(\Phi_{\mathrm{CL}} \times 10^{4}\right)$ of the PO-CL for eight oxalates enhanced by DSBs (1b-f). ${ }^{a}$

\begin{tabular}{lcccccccc}
\hline \multicolumn{1}{c}{ DSB } & TCPO & 2,4-DCPO & $2,6-D C P O$ & 4 -CPO & 2-CPO & DNPO & DPO & 4CPPO \\
\hline Ib $(\mathrm{R}=\mathrm{OMe})$ & 1.12 & 6.30 & 1.01 & 3.63 & 8.68 & 1.06 & 0.29 & 0.72 \\
Ic $(\mathrm{R}=\mathrm{Me})$ & 0.55 & 2.38 & 0.61 & 1.36 & 3.97 & 0.54 & 0.16 & 0.30 \\
Id $(\mathrm{R}=\mathrm{H})$ & 0.33 & 1.50 & 0.32 & 0.62 & 1.79 & 0.17 & 0.05 & 0.14 \\
1e $(\mathrm{R}=\mathrm{Cl})$ & 0.27 & 1.00 & 0.29 & 0.50 & 1.58 & 0.11 & 0.04 & 0.11 \\
If $(\mathrm{R}=\mathrm{CN})$ & 0.11 & 0.25 & 0.10 & 0.15 & 0.41 & 0.04 & 0.02 & 0.04 \\
\hline
\end{tabular}

${ }^{a}$ oxalate $]=3.75 \times 10^{-6} \mathrm{M},[\mathrm{DSB}]=7.5 \times 10^{-6} \mathrm{M},\left[\mathrm{H}_{2} \mathrm{O}_{2}\right]=2.5 \times 10^{-3} \mathrm{M},\left[\mathrm{Na}_{2} \mathrm{CO}_{3}\right]=7.5 \times 10^{-5} \mathrm{M}$.

\section{Table 4}

The $\rho$-values and the pseudo-first-order rate constants of the CL decays of the eight oxalates enhanced by $\mathbf{1 b}$.

\begin{tabular}{lcc}
\hline oxalate & $\rho$-value & $\begin{array}{c}\text { pseudo-first-order decay rate } \\
k\left(\mathrm{sec}^{-1}\right)\end{array}$ \\
\hline TCPO & -0.65 & 1.18 \\
2,4-DCPO & -0.90 & 12.56 \\
2,6-DCPO & -0.63 & 0.38 \\
4-CPO & -0.90 & 5.40 \\
2-CPO & -0.87 & 9.28 \\
DNPO & -1.01 & 16.27 \\
DPO & -0.84 & 0.65 \\
4-CPPO & -0.84 & 4.28 \\
\hline
\end{tabular}

\footnotetext{
${ }^{a}$ Standard deviations $\left(R^{2}\right)$ are described in Fig. 5.
} 